\title{
Electrochemical Determination of Amsacrine at a ds-DNA Modified Graphene Carbon Paste Electrode and its Application as a Label-free Electrochemical Biosensor
}

\author{
Hadi Mahmoudi Moghaddam ${ }^{1 *}$, Hadi Beitollahi ${ }^{2}$, Gholamreza Dehghannoudeh ${ }^{1,3 *}$ and \\ Hamid Forootanfar ${ }^{1,4}$ \\ ${ }^{1}$ Pharmaceutics Research Center, Institute of Neuropharmacology, Kerman University of Medical \\ Sciences, Kerman, Iran \\ ${ }^{2}$ Environment Department, Institute of Science and High Technology and Environmental Sciences, \\ Graduate University of Advanced Technology, Kerman, Iran \\ ${ }^{3}$ Department of Pharmaceutics, School of Pharmacy, Kerman University of Medical Sciences, Kerman, \\ Iran \\ ${ }^{4}$ Department of Pharmaceutical Biotechnology, Faculty of Pharmacy, Kerman University of Medical \\ Sciences, Kerman, Iran \\ *E-mail: h.mahmoudi4@yahoo.com, ghr_dehghan@kmu.ac.ir, grdehghan@gmail.com
}

doi: $10.20964 / 2017.11 .39$

Received: 11 February 2017 / Accepted: 4 september 2017 / Published: 12 October 2017

The interaction between amsacrine and double stranded deoxyribonucleic acid (ds-DNA) was studied by a graphene paste electrode (GPE) and incubation solution using differential pulse voltammetry (DPV). A simple and sensitive biosensor was made using the mentioned interaction for determining amsacrine. DPV shows a linear dynamic range from $7.0 \times 10^{-7}$ to $1.0 \times 10^{-4} \mathrm{M}$ for amsacrine. The use of this screening method for analyzing real sample was studied with applying the proposed method to determine amsacrine in urine and blood serum. Generally, the findings indicated a DNA sensor with the ability to analyze the amsacrine in real samples effectively.

Keywords: Amsacrine; ds-DNA; Graphene; Carbon paste electrode

\section{$\underline{\text { FULL TEXT }}$}

(C) 2017 The Authors. Published by ESG (www.electrochemsci.org). This article is an open access article distributed under the terms and conditions of the Creative Commons Attribution license (http://creativecommons.org/licenses/by/4.0/). 